Научная статья

УДК 343.35:37.017.4(470)

https://doi.org/10.24866/1813-3274/2021-3/97-110

\title{
ГОСУДАРСТВЕННАЯ АНТИКОРРУПЦИОННАЯ ПОЛИТИКА В СИСТЕМЕ ОТЕЧЕСТВЕННОГО ОБРАЗОВАНИЯ КАК СОЦИАЛЬНО-ПСИХОЛОГИЧЕСКАЯ ОСНОВА ПРЕДУПРЕЖДЕНИЯ КОРРУПЦИИ И КОРРУПЦИОННЫХ ПРЕСТУПЛЕНИЙ В РОССИИ
}

\author{
А. Е. Комиссаров ${ }^{1}$, Казанский (Приволжский) федеральный университет, \\ г. Казань, Россия \\ E-mail: komissarov.ae@mail.ru
}

Аннотащция. В статье рассматривается государственная антикоррупционная политика и её роль в системе отечественного воспитательно-образовательного процесса, актуальность создания и внедрения предлагаемой автором единой государственной антикоррупционной воспитательно-образовательной программы (ЕГАВП) по предупреждению коррупции и коррупционных преступлений в России, которую необходимо проводить через отечественную образовательную систему. Здесь же обосновывается целесообразность внедрения такой программы в российский образовательный процесс и исследуются основные проблемы, стоящие на пути снижения уровня коррупции в данной социальной сфере.

Ключевые слова: антикоррупционная политика, антикоррупционная программа, система образования, высшее образование, коррупционная преступность, коррупция, противодействие коррупции, предупреждение коррупции, взяточничество, получение взятки, дача взятки, посредничество во взяточничестве, единый процесс образования и воспитания, уголовная ответственность за коррупционные преступления и др.

Для цุитирования: Комиссаров А. Е. Государственная антикоррупционная политика в системе отечественного образования как социально-психологическая основа предупреждения коррупции и коррупционных преступлений в России // Азиатско-Тихоокеанский регион: экономика, политика, право. 2021. № 3. С. 97-110. DOI https://doi.org/10.24866/1813-3274/2021-3/97-110.

\footnotetext{
1 Артём Евгеньевич Комиссаров, аспирант кафедры уголовного права юридического факультета Казанского (Приволжского) федерального университета, г. Казань, Россия.

(C) Комиссаров А. Е., 2021
} 
Original article

\title{
STATE ANTI-CORRUPTION POLICY IN THE SYSTEM OF DOMESTIC EDUCATION AS A SOCIO-PSYCHOLOGICAL BASIS FOR THE PREVENTION OF CORRUPTION AND CORRUPTION CRIMES IN RUSSIA
}

\author{
Artem E. Komissarov ${ }^{1}$, Kazan (Volga Region) Federal University
}

Abstract. The article examines the state anti-corruption policy and its role in the system of domestic educational processes, the relevance of the creation and implementation of a unified state anti-corruption educational program, proposed by the author (abbreviated name: "EGAVP"), to prevent corruption and corruption crimes in Russia, which must be carried out through the domestic educational system. It also substantiates the feasibility of introducing such a program into the Russian educational process, and examines the main problems standing in the way of reducing the level of corruption in this social sphere.

Keywords: anti-corruption policy, anti-corruption program, education system, higher education, corruption crime, corruption, anti-corruption, prevention of corruption, bribery, bribery, bribery, mediation in bribery, a unified process of education and upbringing, criminal liability for corruption crimes.

For citing: Komissarov A. E. State Anti-Corruption Policy in the System of Domestic Education as a Socio-Psychological Basis for the Prevention of Corruption and Corruption Crimes in Russia // PACIFIC RIM: Economics, Politics, Law. 2021. No 3. P. 97-110. DOI https://doi.org/10.24866/1813-3274/2021-3/97-110.

И воспитание, и образование нераздельны. Нельзя воспитывать, не передавая знания, всякое же знание действует воспитательно.

Л. Н. Толстой

По сообщению Председателя Следственного комитета Российской Федерации А. И. Бастрыкина, с начала 2020 г. было возбуждено 15217 уголовных дел по коррупционным преступлениям, что на 4 \% больше, чем в 2019 г. [1].

17 июня 2020 г. Генеральный прокурор РФ И. В. Краснов на заседании Совета Федерации РФ сообщил о том, что в России второй год подряд растёт число выяв-

\footnotetext{
${ }^{1}$ Artem E. Komissarov, Post-graduate Student of the Department of Criminal Law, Faculty of Law, Kazan (Volga Region) Federal University, Kazan, Russia.
} 
Комиссаров А. Е. Государственная антикоррупционная политика в системе отечественного образования как социально-психологическая основа предупреждения коррупции и коррупционных преступлений в России

ленных коррупционных преступлений и преступлений коррупционной направленности [2].

Указанные выше сведения нельзя считать точными, так как они не учитывают латентную коррупцию и являются статистическими данными, не отражающими реальное состояние коррупции в России.

Отдельного внимания заслуживают сведения международного антикоррупционного движения «Transparency International». Согласно таковым, Российская Федерация за 2020 г. набрала 30 баллов из 100 возможных и заняла 129-е место из 180 возможных. Такое же количество баллов, к примеру, набрали Габон, Азербайджан, Мали и Малави.

По мнению «Transparency International», Россия много лет занимает далеко не самые высокие места в Индексе восприятия коррупции, что отражает отсутствие в ней системного противодействия коррупции [3].

Нелегко бороться с коррупцией и коррупционными преступлениями, когда коррупция носит системный характер и ею буквально пронизаны все сферы деятельности в России. Не исключением является и сфера образования, в частности образовательные организации высшего образования России.

Рост коррупции происходит уже на уровне генетики: вырастает всё новое и новое поколение людей, подверженное этому «недугу», что придаёт этой «социальной болезни» особую устойчивость и развитие, как своего рода «наследственному заболеванию», плохо поддающемуся «лечению», перерастающему в скрытую форму «масштабной социальной эпидемии». Особое опасение вызывает то, что в среде этих поколений людей сложились свои устоявшиеся «коррупционные обычаи, традиции» «делового оборота».

Как сказано в п.п. 1, 2, 3 ст. 2 Федерального закона от 29.12.2012 № 273-Ф3 «Об образовании в Российской Федерации»: «1) образование - единый целенаправленный процесс воспитания и обучения, являющийся общественно значимым благом и осуществляемый в интересах человека, семьи, общества и государства, а также совокупность приобретаемых знаний, умений, навыков, ценностных установок, опыта деятельности и компетенции определённых объёма и сложности в целях интеллектуального, духовно-нравственного, творческого, физического и (или) профессионального развития человека, удовлетворения его образовательных потребностей и интересов»;

2) воспитание - деятельность, направленная на развитие личности, создание условий для самоопределения и социализации, обучающихся на основе социокультурных, духовно-нравственных ценностей и принятых в российском обществе правил и норм поведения в интересах человека, семьи, общества и государства, формирование у обучающихся чувства патриотизма, гражданственности, уважения к памяти защитников Отечества и подвигам Героев Отечества, закону и правопоряд- 
ку, человеку труда и старшему поколению, взаимного уважения, бережного отношения к культурному наследию и традициям многонационального народа Российской Федерации, природе и окружающей среде;

3) обучение - целенаправленный процесс организации деятельности обучающихся по овладению знаниями, умениями, навыками и компетенцией, приобретению опыта деятельности, развитию способностей, приобретению опыта применения знаний в повседневной жизни и формированию у обучающихся мотивации получения образования в течение всей жизни» [4].

Законодатель признаёт, что по сути образование включает в себя, наряду с обучением, и воспитание. Эти элементы неразделимы и направлены к единой цели: становлению полноценной духовно-нравственной личности, обладающей современным уровнем знаний. Образование осуществляется не только в интересах отдельной личности, но и в интересах общества, государства, человеческой цивилизации, устойчивого прогресса в развитии человечества в целом.

Формирование личности человека начинается с самых малых лет его жизни. На формирование целостной и полноценной личности человека существенное влияние оказывает воспитание, наряду с обучением и образованием, которое человек получает от родителей, лиц, выполняющих их функции, а также от педагогических работников образовательных организаций на всех уровнях образования и воспитания. Немаловажную роль в формировании личности человека также играет то, в какой среде он рос, воспитывался, какую модель поведения при этом перенимал как пример для подражания, и то, в какую среду попадёт в дальнейшем. Только нравственно «здоровая», то есть устойчивая к различным негативным, в том числе коррупционным проявлениям, «образовательная среда», созданная на базе образовательных организаций всех уровней образования, начиная с дошкольного, способна внести свой существенный вклад в формирование духовно-нравственной личности обучающегося и воспитания в нём нетерпимости к коррупционным проявлениям. Чем больше будет людей, обладающих нетерпимостью к коррупционным проявлениям, тем меньше будет людей, подверженных коррупции.

Несмотря на то, что коррупция является «системным социальным заболеванием», которое поразило в нашей стране все сферы деятельности, в том числе образовательную, тем не менее, существенный вклад и соответствующие позитивные плоды может принести планомерная системная работа по предупреждению коррупции и коррупционных преступлений, которая должна проводиться в первую очередь именно через образовательную систему, на всех уровнях образования и на всех этапах воспитания подрастающей молодёжи.

Само наличие коррупционных проявлений в образовании, как и в других общественных сферах, затрудняет работу, направленную на предупреждение корруп- 
Комиссаров А. Е. Государственная антикоррупционная политика в системе отечественного образования как социально-психологическая основа предупреждения коррупции и коррупционных преступлений в России

ции и коррупционных преступлений. Наличие коррупции в образовательной сфере причиняет существенный вред развитию и формированию личности человека. Попадая в такую «коррупционную среду», обучающийся подвергается высокому риску «заражения» этой «системной болезнью».

Наличие коррупции в образовании оказывает негативное влияние на формирование ложных ценностей, принципов и убеждений. У обучающегося, сталкивающегося с коррупционными проявлениями в стенах образовательной организации, создаются условия, необходимые для применения полученных «коррупционных знаний» на практике.

За исторический период борьбы с коррупцией в России было принято множество различных нормативно-правовых актов и поправок к ним, направленных на противодействие этому социально-негативному явлению, в частности, Федеральный закон «О противодействии коррупции» от 25.12.2008 № 273-Ф3 (ред. от 26.05.2021 г.); Указ Президента РФ от 16.08.2021 № 478 «О Национальном плане противодействия коррупции на 2021-2024 годы» и т.д.

Исследованию коррупции как одной из угроз национальной безопасности Российской Федерации было посвящено немало трудов [5; 6 и др.].

Особое отношение государства к такому антисоциальному явлению, как коррупция, отражено в Стратегии национальной безопасности Российской Федерации, принятой в 2021 г., где коррупция, по сути, признаётся государством одной из системных угроз для безопасности Российской Федерации.

Кроме того, полагаем необходимым отметить и особо значимые политические аспекты, затрагивающие тематику нашего исследования, которые, в частности, находят своё отражение в документе «О Стратегии национальной безопасности Российской Федерации» (утв. Указом Президента РФ от 02.07.2021 г. № 400) (далее - Стратегия), а именно:

- в подп. 3 пункта 25 отмечено, что национальными интересами России на современном этапе, наряду с поддержанием гражданского мира и согласия в стране, укрепления законности, являются, в частности, и такие, как искоренение коррупции;

- в пункте 45 указывается, что на фоне сохраняющихся социально-экономических проблем необходимо усилить борьбу с коррупцией;

- в пункте 46 указывается, что одной из целей обеспечения государственной и общественной безопасности является искоренение коррупции;

- пункт 47 гласит, что достижение целей обеспечения государственной и общественной безопасности осуществляется путём реализации государственной политики, направленной на решение таких задач, как, в частности (подп. 13), предупреждение и пресечение преступлений коррупционной направленности;

- в пункте 67 указано, что достижение целей обеспечения экономической безопасности России осуществляется путём решения целого ряда задач, и в частности 
(подп. 30), снижения доли теневого и криминального секторов экономики, а также уровня коррупции в предпринимательской среде;

- в подп. 25 пункта 101 сказано, что для достижения целей внешней политики России необходимо решение таких задач, как развитие международного сотрудничества в области противодействия терроризму, экстремизму, коррупции, незаконному производству и обороту наркотических средств и психотропных веществ, нелегальной миграции, трансграничной преступности.

Коррупция является одной из основных угроз для национальной безопасности России.

Само наличие коррупции в образовании, особенно в образовательных организациях высшего образования нашей страны, является одним из основных источников зарождения и развития коррупции в целом, так как обучение в образовательных организациях, наряду с воспитанием подрастающего поколения, оказывает непосредственное влияние на формирование основных устойчивых качеств личности человека.

Что отрадно, в Стратегии особое внимание уделяется и образовательной системе:

- в пункте 14 Стратегии указывается, что для перехода России на новый уровень экономического развития и повышения качества жизни граждан необходимо, в частности, развивать научный потенциал, повышать качество и доступность образования;

- в пункте 22 указывается, что состояние науки и образования является своеобразным индикатором конкурентоспособности России на международной арене, а выход на передовые позиции в этих областях будет способствовать достижению национальных целей развития и созданию условий для повышения международного авторитета России.

- согласно пункту 32 целями государственной политики в сфере сбережения народа России и развития человеческого потенциала являются устойчивый естественный рост численности и повышение качества жизни населения, укрепление здоровья граждан, сокращение бедности, снижение уровня социального и имущественного неравенства, повышение уровня образования населения, воспитание гармонично развитого и социально ответственного гражданина.

- в подп. 12-13 пункта 33 указано, что достижение целей государственной политики в сфере сбережения народа России и развития человеческого потенциала обеспечивается путём решения такой задачи, как повышение качества общего образования; предоставление гражданам широких возможностей для получения среднего и высшего профессионального образования, профессиональной подготовки и переподготовки на протяжении всей жизни в соответствии с потребностями рынка труда;

- в пункте 71 указывается, что новых условиях появляются и становятся востребованными новые профессии, растут требования к уровню образования и ква- 
Комиссаров А. Е. Государственная антикоррупционная политика в системе отечественного образования как социально-психологическая основа предупреждения коррупции и коррупционных преступлений в России

лификации работников. Межгосударственная конкуренция за привлечение учёных и высококвалифицированных специалистов усиливается;

- в подп. 8 пункта 76 сказано, что для достижения цели научнотехнологического развития России необходимо решение таких задач, как, в частности, обновление материально-технической базы научных организаций и образовательных организаций высшего образования, в том числе приборной и экспериментально-испытательной; а в подп. 24 пункта 76 отмечается необходимость развития системы среднего профессионального образования в целях подготовки квалифицированных рабочих и специалистов среднего звена в соответствии с современными мировыми стандартами.

- в пункте 86 параграфа «Защита российских духовно-нравственных ценностей, культуры и исторической памяти» указывается, что насаждение чуждых идеалов и ценностей, осуществление без учёта исторических традиций и опыта предшествующих поколений реформ в области образования, науки, культуры, религии, языка и информационной деятельности приводят к усилению разобщенности и поляризации национальных обществ, разрушают фундамент культурного суверенитета, подрывают основы политической стабильности и государственности. Пересмотр базовых норм морали, психологическое манипулирование наносят непоправимый ущерб нравственному здоровью человека, поощряют деструктивное поведение, формируют условия для саморазрушения общества. Увеличивается разрыв между поколениями. Одновременно нарастают проявления агрессивного национализма, ксенофобии, религиозного экстремизма и терроризма.

- согласно подп. 5 пункта 93 защита традиционных российских духовнонравственных ценностей, культуры и исторической памяти обеспечивается путем решения, в частности, таких задач, как развитие системы образования, обучения и воспитания как основы формирования развитой и социально ответственной личности, стремящейся к духовному, нравственному, интеллектуальному и физическому совершенству [7].

Исходя из анализа положений, отражённых в Стратегии национальной безопасности Российской Федерации (утв. Указом Президента РФ от 02.07.2021 г. № 400); Федеральном законе «О противодействии коррупции» от 25.12.2008 № 273-Ф3; Федеральном законе «Об образовании в Российской Федерации» от 29.12.2012 № 273-Ф3 и ряда других нормативных правовых актов следует вывод, что государство, по сути, придаёт образовательной системе стратегическое значение для национальной безопасности Российской Федерации.

Конечно же, принятие различных нормативно-правовых актов и поправок к ним, направленных на противодействие этому социально-негативному явлению приносит определённые позитивные плоды. Так, в СМИ не перестаёт поступать информация о задержаниях и «посадках» высокопоставленных представителей 
властных структур и иных руководителей различных учреждений и организаций России в центре и на местах за опасные виды коррупционных преступлений.

Сколько ни вводи различных запретов и ограничений, они, если и будут соблюдаться, то формально, либо их и вовсе будут обходить в связи с отсутствием у субъекта, вступающего в коррупционные отношения, личностной нетерпимости к коррупции и решимости противостоять ей. Эти личные качества неразрывно связаны с духовно-нравственными особенностями личности человека, подвергающегося коррупционному воздействию.

Коррупция - это аморальное, особо опасное социальное явление (качество) в каждом обществе и в международном сообществе, свидетельствующее о моральном разложении должностных лиц, иностранных должностных лиц, должностных лиц публичных международных организаций, подрывающее их авторитет в массах, искажающее их этические ценности, отношения справедливости, наносящее ущерб устойчивому прогрессивному развитию и общественному порядку, тесно связанное с организованной и экономической преступностью, проявляющееся в системном использовании ими своего служебного положения и связанных с ним возможностей в целях извлечения материальной (имущественной) выгоды для себя, другого физического или юридического лица либо группы лиц [8, с. 114].

Назрела острая необходимость в создании и внедрении единой государственной антикоррупционной воспитательно-образовательной программы, сокращённо ЕГАВП на базе единого отечественного образования и воспитания, направленной на противодействие и предупреждение этого «системного опасного социального заболевания», на нравственное «оздоровление» уже «заразившихся» членов общества.

Единая государственная антикоррупционная воспитательно-образовательная программа должна быть не факультативным, а обязательным и непрерывным курсом (предметом) обучения и воспитания для освоения обучающимися на всех уровнях предметного образования, начиная с дошкольного.

ЕГАВП, помимо самостоятельного курса (предмета) обучения, должна быть интегрирована в уже существующие предметы (дисциплины), к примеру, такие, как история, обществознание, психология, экономика, юриспруденция, философия и др.

Внутренние документы, принятые различными образовательными организациями, учреждениями, направленные на противодействие и предупреждение коррупции, не должны подменять единую государственную антикоррупционную воспитательно-образовательную программу. С внедрением ЕГАВП на базе образовательных организаций и учреждений должны быть приняты и иные необходимые внутренние локальные акты, соответствующие её требованиям. При этом все ранее принятые внутренние юридические документы должны быть приведены в соответствие с требованиями, предъявляемыми ЕГАВП. 
Комиссаров А. Е. Государственная антикоррупционная политика в системе отечественного образования как социально-психологическая основа предупреждения коррупции и коррупционных преступлений в России

Откладывать внедрение ЕГАВП недопустимо по той причине, что ощутимые результаты от её применения, которые должны выражаться в фактическом, а не статистическом снижении уровня коррупции, могут появиться не сразу. Для этого необходимы основные и наиболее эффективные меры противодействия, направленные на основные объективные причины негативного развития общественных отношений собственности, её происхождения в условиях господства частной собственности и частнособственнических отношений капитализма с его криминальной природой и происхождением.

Основная цель ЕГАВП - посильное воспитание духовно-нравственной личности и формирование антикоррупционного мировоззрения и соответствующего поведения со своей чёткой гражданской позицией в условиях неблагоприятной для этого действительности. Стремление к её достижению может дать положительные результаты, которые должны привести к снижению коррупционной зависимости российского общества и развитию тенденции уменьшения коррупции и её проявлений в стране.

\section{Основные задачи ЕГАВП:}

- донести до подавляющего числа российских граждан общее представление о сущности коррупции, её формах;

- разъяснить им особенности проявления коррупции в различных сферах общественной жизни, её причины и социально опасные последствия;

- научить как можно большее число россиян распознавать коррупцию;

- сформировать у граждан навыки адекватного анализа и личностной оценки данного социального явления и лиц, занятых в системной коррупции;

- получить комплекс необходимых знаний о типичных коррупциогенных ситуациях для формирования стандартов поведения в таких ситуациях в соответствии с правовыми и морально-этическими нормами;

- всячески мотивировать к антикоррупционному поведению;

- формировать нетерпимость к любым проявлениям коррупции;

- сформировать основы правовой грамотности, связанной с коррупционными отношениями, там, где они стали фактами социальной действительности.

Основные этапы государственной антикоррупционной воспитательнообразовательной программы делятся на:

1) Дошкольное образование (воспитательно-образовательный процесс): получение знаний и воспитание таких личных качеств у обучающихся, как совесть, справедливость, честность, ответственность, уважение к людям, доброта, и формирование приоритета духовно-нравственных ценностей перед материальными. Такие тематические занятия с детьми этого возраста могут проходить в виде пересказов сказок, рассказов, книг, а также путём проведения театральных и иных представлений с последующим обсуждением с ребятами их смысла. В указанных мероприяти- 
ях, помимо воспитателя либо педагога-воспитателя, необходимо участие детского психолога, имеющего соответствующую аккредитацию и предметные знания в этой области;

2) Образование и продолжение воспитания на этапе школьного обучения:

- внедрение предмета «антикоррупционная этика» и предмета «правовое воспитание»;

- проведение антикоррупционных тематических театральных и иных представлений с последующим обсуждением их смысла;

- проведение антикоррупционных тематических игр. К примеру, их можно назвать «суд над коррупционером», «расследование коррупционного дела» и т.п. с последующим обсуждением их смысла;

- проведение промежуточной и итоговой оценки полученных знаний;

- доступное проведение периодического мониторинга уровня коррупции, с которым приходится сталкиваться обучающимся в процессе обучения и в повседневной жизни в виде анонимного тестирования и анкетирования обучающихся и их родителей (законных представителей).

В указанных мероприятиях (помимо педагога либо классного руководителя) необходимо участие детского психолога, имеющего соответствующую аккредитацию и предметные знания в этой области. С целью более предметного обучения практическим основам антикоррупционного поведения для участия в антикоррупционных учебных мероприятиях необходимо привлекать сотрудников правоохранительных органов, в компетенцию которых входит расследование коррупционных преступлений и преступлений коррупционной направленности;

3) Среднее профессиональное, высшее и последующее образование: преподавание курса «антикоррупционная этика» в соответствии с уровнем образования, а также проведение занятий в более традиционных формах (к примеру, проведение тематических лекций с привлечением сотрудников правоохранительных органов, в компетенцию которых входит расследование коррупционных преступлений и преступлений коррупционной направленности, семинаров, дискуссий с обязательным участием обучающихся в смоделированных коррупционных ситуативных занятиях с последующим обсуждением их смысла). При этом необходимо проводить промежуточную и итоговую оценку знаний. Также желательно проводить систематический мониторинг уровня коррупции, с которым приходится сталкиваться обучающимся в процессе обучения и в повседневной жизни в виде анонимного тестирования и анкетирования обучающихся и их родителей (законных представителей).

Для полноценного и всестороннего усвоения ЕГАВП обучающимися необходимо поэтапно, начиная со школьной скамьи, в рамках воспитательнообразовательной программы вводить правовое воспитание из таких областей права, как гражданское, административное, уголовное, трудовое, семейное. 
Комиссаров А. Е. Государственная антикоррупционная политика в системе отечественного образования как социально-психологическая основа предупреждения коррупции и коррупционных преступлений в России

Правовое воспитание необходимо для разъяснения обучающимся природы коррупции, её последствий, а также для обучения умению аргументированно отстаивать свои права и свою позицию законными способами, без коррупционной составляющей, умению находить пути преодоления коррупционных проявлений при решении жизненно необходимых вопросов в учёбе, работе и повседневной действительности.

Среди обучающихся следует создать «моду» на «культ личности честного человека», поступающего «по совести», привить отрицательное отношение лица, вступающего в коррупционные отношения, к явлению коррупции.

Можно установить доску почёта и доску порицания с заголовками статей из СМИ и информацией из открытых источников правоохранительных органов о подтвердившихся фактах коррупции в образовательных организациях.

Желательно создать единый реестр лиц, уволенных за коррупционные проявления из образовательных организаций России, по аналогии с созданным реестром лиц, уволенных в связи с утратой доверия, которые размещены на официальном сайте портала госслужбы [9].

Необходимо многое сделать и для развития самого антикоррупционного образования (поднять его качество, авторитет, обеспечить достойную заработную плату педагогическим работникам образовательных организаций и др.). Педагогический работник не должен постоянно думать о том, как прокормить свою семью и себя, он должен со спокойной совестью трудиться и быть уверенным в том, что его миссия имеет для государства стратегическое значение. Низкая заработная плата педагогических работников является, особенно при прочих равных условиях, провоцирующим коррупциогенным фактором. Кроме того, получая низкую заработную плату, педагогические работники вынуждены отыскивать дополнительные источники заработков, что, в свою очередь, сказывается на качестве образования и провоцирует педагога на получение незаконного дополнительного вознаграждения.

Назрела острая необходимость в воспроизводстве, обновлении и развитии отечественного образования, во внедрении на его базе ЕГАВП, которая должна способствовать постепенному снижению уровня коррупции и коррупционных проявлений, как внутри самой системы образования, так и в целом в России.

С участием учёных-правоведов началась работа по принятию программ антикоррупционного воспитания, совмещённого с предметным обучением, для выработки со школьной скамьи чувства неприязни к взяткам, а в вузах планируется внедрить курс антикоррупционной этики [10].

Экономическая целесообразность создания и внедрения ЕГАВП на базе обновленной образовательной системы выглядит намного эффективнее, чем если бы похожая программа со схожими целями и задачами была создана как самостоятель- 
ный и отдельный инструмент, существующий вне системы образования. У системы образования имеется необходимый потенциал, а также площадка для внедрения этой программы. Потребуется меньше усилий и финансовых затрат для достижения необходимых целей комплексного воспитания и обучения в едином взаимосвязанном процессе.

Основные положения единого позитивного воспитательно-образовательного процесса, предлагаемого нами, уже так или иначе были опробованы в советской действительности, в педагогической деятельности наших лучших педагогов и воспитателей, успешно противодействовавших и управлявших процессом противодействия взяточничеству и другим коррупционным преступлениям в процессе учебновоспитательной работы и формирования позитивно направленной личности в процессе обучения и воспитания дошкольников, школьников, студентов, магистрантов и аспирантов. Эту всемирно известную, лучшую в мире школу профилактики коррупционных и других корыстных преступлений заложили отечественные педагоги воспитатели и учёные К. Д. Ушинский, А. С. Макаренко, В. А. Сухомлинский и некоторые другие. Огромную положительную роль для отечественной криминологии и педагогики сыграли работы А. С. Макаренко: «Педагогическая поэма» (1935г.), «Книга для родителей» (1937 г.), «Флаги на башнях» (1938 г.) и др.; учёные труды К. Д. Ушинского: «Человек как предмет воспитания» (1867-1869 гг.) и др.; В. А. Сухомлинского: «Формирование коммунистических убеждений молодого поколения» (1961 г.), «Воспитание личности в советской школе» (1965 г.), «Сердце отдаю детям» (1969 г.), «Рождение гражданина» (1970 г.), «О воспитании» (1973 г.) и др.

Формирование позитивно направленной личности граждан, которых не привлекает коррупция и корыстный криминал, в советское время опиралось на объективно позитивное воспитание, где такие личные качества, как жадность, эгоизм, высокомерие и властолюбие в учебно-воспитательном процессе отмечались как отрицательные, а доброта, взаимопонимание, взаимное уважение и взаимопомощь являлись стимулами, на которых базировалось позитивное воспитание советских людей.

Объективной основой позитивного социалистического воспитания советских людей служили: социалистический социально-экономический уклад жизни и его государственная и общественная система власти, сама социалистическая система хозяйствования и коммунистическая нравственность, исходящая из служения Родине и народу, тем отношениям, которые были ведущими силами при формировании позитивной, добротворческой личности, лишенной эгоизма, злобы и корыстолюбия. И нам необходимо сейчас использовать лучшее из достигнутого ранее. 
Комиссаров А. Е. Государственная антикоррупционная политика в системе отечественного образования как социально-психологическая основа предупреждения коррупции и коррупционных преступлений в России

\section{Список литературы}

1. В России стали возбуждать больше дел о коррупции, рассказал глава CK. - URL: https://ria.ru/20201208/korruptsiya-1588130508.html (дата обращения: 07.03.2021 г.).

2. Краснов, И. Генпрокурор заявил о росте числа выявляемых случаев коррупции в России. - URL: https://ria.ru/20200617/1573057184.html (дата обращения: 07.03.2021).

3. Transparency International: Россия в Индексе восприятия коррупции - 2020. URL: https://transparency.org.ru/research/indeks-vospriyatiya-korruptsii/rossiya-v-indeks e-vospriyatiya-korruptsii-2020-30-ballov-i-129-mesto.html (дата обращения: 07.03.2021г.).

4. Об образовании в Российской Федерации : Федеральный закон от 29 декабря 2012 г. № 273-ФЗ (ред. от 17.02.2021) // СПС Гарант.

5. Егорова, А. С. Коррупция в правоохранительных органах как угроза национальной безопасности Российской Федерации // Международный научноисследовательский журнал. - 2016. - № 4-7 (46). - С. 147-149.

6. Дудник, И. М. Коррупция как угроза национальной безопасности Российской Федерации // Актуальные проблемы права и экономики : сборник научных трудов. - Саратов, 2016. - С. 113-115.

7. О Стратегии национальной безопасности Российской Федерации : указ Президента РФ от 02 июля 2021 г. № 400 // Собрание законодательства Российской Федерации. - 2021. - № 27 (часть II). - Ст. 5351.

8. Сидоров, Б. В. Правильное определение моральной и социально-правовой природы коррупции, её признаков и форм отражения в действительности основная юридическая предпосылка успешной антикоррупционной деятельности / Б. В. Сидоров, А. Е. Комиссаров // Вестник экономики, права и социологии. 2018. - № 3. - С. 111-116.

9. Реестр лиц, уволенных в связи с утратой доверия. - URL: https://gossluzhba.gov.ru/reestr (дата обращения: 07.03.2021).

10. Взятка - это токсично. В школах и вузах начнут учить борьбе с коррупцией. - URL: https://rg.ru/2019/03/20/v-shkolah-i-vuzah-nachnut-uchit-borbe-skorrup ciej.html (дата обращения: 07.03.2021).

\section{References}

1. In Russia began to initiate more cases of corruption, said the head of the Investigative Committee. Available at: https://ria.ru/20201208/korruptsiya-1588130508.html (accessed 03 July 2021). (In Russia).

2. Krasnov I. Genprokuror zayavil o roste chisla vyyavlyaemykh sluchaev korruptsii $v$ Rossii [Prosecutor General announced an increase in the number of detected cases of corruption in Russia]. Available at: https://ria.ru/20200617/1573057184.html (accessed 03 July 2021). 
3. Transparency International: Russia in the Corruption Perceptions Index - 2020. Available at: https://transparency.org.ru/research/indeks-vospriyatiya-korruptsii/rossiyav-indekse-vospriyatiya-korruptsii-2020-30-ballov-i-129-mesto.html (accessed 03 July 2021). (In Russian).

4. On education in the Russian Federation: Federal Law of December 29, 2012 No. 273-FZ (as amended on February 17, 2021). Reference Search System Garant. (In Russian).

5. Egorova A. S. Korruptsiya v pravookhranitel'nykh organakh kak ugroza natsional'noi bezopasnosti Rossiiskoi Federatsii [Corruption in law enforcement agencies as a threat to the national security of the Russian Federation]. Mezhdunarodnyi nauchnoissledovatel'skii zhurnal, 2016, no. 4-7 (46), pp. 147-149.

6. Dudnik I. M. Korruptsiya kak ugroza natsional'noi bezopasnosti Rossiiskoi Federatsii [Corruption as a threat to the national security of the Russian Federation]. Aktual'nye problemy prava i ekonomiki: sbornik nauchnykh trudov [Actual problems of law and economics: collection of scientific papers]. Saratov, 2016, pp 113-115.

7. On the National Security Strategy of the Russian Federation: Decree of the President of the Russian Federation of 02.07.2021 No. 400. Collected Legislation of the Russian Federation, 2021, no. 27 (part II), art. 5351. (In Russian).

8. Sidorov B. V., Komissarov A. E. Pravil'noe opredelenie moral'noi i sotsial'nopravovoi prirody korruptsii, ee priznakov i form otrazheniya v deistvitel'nosti - osnovnaya yuridicheskaya predposylka uspeshnoi antikorruptsionnoi deyatel'nosti [Correct definition of the moral and socio-legal nature of corruption, its signs and forms of reflection in reality is the main legal prerequisite for successful anti-corruption activities. Vestnik ekonomiki, prava i sotsiologii.Bulletin of Economics, Law and Sociology, 2018, no. 3, pp. 111-116.

9. Register of persons dismissed due to loss of trust. Available at: https://gossluzhba.gov.ru/reestr (accessed 03 July 2021). (In Russian).

10. A bribe is toxic. Schools and universities will begin to teach the fight against corruption. Available at: https://rg.ru/2019/03/20/v-shkolah-i-vuzah-nachnut-uchit-borbes-korrupciej.html (accessed 03 July 2021). (In Russian). 